\title{
Is Brain Natriuretic Peptide a Reliable Biomarker of Hydration Status in All Peritoneal Dialysis Patients?
}

\author{
Carlo Crepaldi ${ }^{a}$ b Mitchel Rosner ${ }^{c}$ Catarina Teixeira ${ }^{b}$ Lourdes Blanca Martos $^{b}$ \\ Francesca Katiana Martino $^{\mathrm{a}, \mathrm{b}}$ Maria Pia Rodighiero ${ }^{\mathrm{a}, \mathrm{b}}$ Claudio Ronco ${ }^{\mathrm{a}}$ b \\ ${ }^{a}$ Department of Nephrology, Ospedale S. Bortolo, and b International Renal Research Institute of Vicenza, Vicenza, \\ Italy; ' Department of Nephrology and Internal Medicine, University of Virginia, Charlottesville, Va., USA
}

\section{Key Words}

Hydration status · Brain natriuretic peptide · Bioimpedance spectroscopy · Peritoneal dialysis

\begin{abstract}
Background: Achievement of euvolemia is a fundamental challenge in the peritoneal dialysis (PD) population. Bioimpedance spectroscopy (BIS) is one of the best techniques for routine assessment of hydration status (HS) in PD, but in recent years, the role of brain natriuretic peptides (BNP) in the assessment of volume status has gained interest. The aim of this study was to investigate the relation between BNP and volume status as measured by BIS in PD patients and to assess how these variables correlate according to the time that a patient has been on PD. Methods: We prospectively studied 68 PD patients from whom measurements of BNP and assessments of HS by BIS were performed every 3 months. Three groups were defined based on HS: group A, measurements of $\mathrm{HS}<-1.1$ liters (underhydrated); group $B$, measurements of HS between -1.1 and +1.1 liters (normohydrated), and group C, measurements of HS $>+1.1$ liters (overhydrated). Measurements were also separated according to
\end{abstract}

the time on PD ( $<6$ vs. $\geq 6$ months). Correlation between HS and BNP was performed using Spearman's correlation. Results: We performed a total of 478 measurements of HS and BNP. There was a statistically significant difference in BNP $(p<0.001)$ among three HS groups, with higher levels of BNP detected in overhydrated patients. We found a positive correlation between HS and BNP $\left(r_{s}=0.28 ; p<0.001\right)$ that seemed stronger in the first 6 months on PD $\left(r_{s}=0.42 ; p=\right.$ 0.006). Conclusions: BNP correlated positively with fluid overload measured by HS, and this correlation was stronger in the first 6 months on PD.

๑ 2014 S. Karger AG, Basel

\section{Introduction}

The assessment and achievement of an optimal body volume status ('dry weight') in peritoneal dialysis (PD) patients is extremely complex. A validated definition of 'dry' or ideal body weight for PD patients does not exist. Krediet [1] suggested to define optimal volume status as the weight associated with a normal extracellular water (ECW), however this complex determination depends on

\section{KARGER}

E-Mail karger@karger.com www.karger.com/bpu
(C) 2014 S. Karger AG, Basel

0253-5068/14/0373-0238\$39.50/0
Claudio Ronco

Department of Nephrology, Dialysis and Transplantation IRRIV, San Bortolo Hospital

Viale Rodolfi, 37, IT-36100 Vicenza (Italy)

E-Mail cronco@goldnet.it 
the specific methods utilized that are costly and not readily available. An alternative, effective technique to assess extracellular, intracellular and total body water (TBW) is bioelectrical impedance analysis (BIA) [2]. BIA is a nonexpensive and non-invasive technique that has shown to be reproducible, easy to perform and accurate $[3,4]$. At the present, bioelectrical impedance vector analysis (BIVA) or bioelectrical impedance spectroscopy (BIS) are probably among the best tools to perform an 'everyday' assessment of hydration status (HS) on PD patients $[2,5]$. However, this measurement does require training and time to perform. Ideally, serum biomarkers of volume status could supplement this measurement.

Brain natriuretic peptide (BNP) and N-terminal probrain natriuretic peptide (NT-pro-BNP) provide strong prognostic information in patients with heart failure, stable coronary artery disease and acute coronary syndrome [6]. In chronic kidney disease (CKD), their concentrations are often elevated due to high prevalence of ventricular dysfunction and hypertrophy, but also because of impaired renal clearance [7]. These molecules have been extensively associated with increased cardiovascular and overall mortality in hemodialysis and PD patients [8-12]. Their association with fluid overload was also studied in the last decade [13-16], but many questions regarding their usefulness for assessment of dry weight remain [17].

The aim of the present study was to investigate the relationship between BNP levels and volume status measured by BIS in a PD population and to assess how these variables might change and correlate with the time that a patient has been performing PD.

\section{Methods}

\section{Study Design and Data Collection}

We prospectively collected data on PD patients from a single North-East Italian Center between January 2009 and January 2012. All adult, prevalent and incident PD patients were eligible. Exclusion criteria included the presence of any class of heart failure defined by the New York Heart Association classification, history of major cardiovascular events, limb amputation and pacemaker or defibrillator implantation. Evaluation of HS by BIS and blood sampling for determination of the serum BNP levels were performed every 3 months, during scheduled routine visits. Measurements of HS were performed by BIS with Body Composition Monitor ${ }^{\circledR}$ (BCM) (Fresenius Medical Care, Bad Homburg, Germany): patients were in a supine position and after appropriate skin cleaning, electrodes were placed on ipsilateral foot, ankle, hand and wrist. BNP analysis was performed by chemiluminescence immunoassay with Siemens Centaur $\mathrm{XP}^{\circledR}$ device (Diamond Diagnostics, Holliston, Mass., USA). Both HS and BNP measurements were performed in the same day, with dialysate dwelling in the abdomen.
Additional data was collected, including demographics, etiology of $\mathrm{CKD}$, duration of renal replacement therapy and PD, PD modality and use/dose of furosemide. The institutional review board waived the need for informed consent due to the non-interventional nature of the study and the normal application of the methods in the clinical routine for patient care.

\section{Definitions}

The HS was determined by BCM and expressed as HS in liters. According to BIS HS, three groups of hydration were defined based on the reference ranges for human body composition from previous studies [18]: group A (underhydration) included measurements with HS <-1.1 liters, group B (euvolumia) included measurements with HS between -1.1 and +1.1 liters, and group $\mathrm{C}$ (overhydration) included measurements with $\mathrm{HS}>+1.1$ liters. We also performed a separate analysis according to the time on PD: for this purpose we separated the measurements performed in patients on $\mathrm{PD}$ for $<6$ months from the ones performed in patients on $\mathrm{PD}$ for a period $\geq 6$ months.

\section{Statistical Analysis}

The normality of data was assessed by the KolmogorovSmirnov test. Continuous variables are expressed as mean \pm SD or median (interquartile range) and compared between any two groups using a t test or Mann-Whitney $U$ test, and among three groups using analysis of variance or Kruskal-Wallis $\mathrm{H}$ test, as appropriate. Categorical variables are expressed as number of cases and proportion and compared with the Mantel-Haenszel $\chi^{2}$ test or Fisher's exact test. A Spearman's rank order correlation was run to determine the relationship between BNP and HS. All statistical analyses were performed using the SPSS 17.0 software package (SPSS, Inc., Chicago, Ill., USA), with a two-sided $p$ value $<0.05$ considered as statistically significant.

\section{Results}

During the study period, 175 patients were treated with PD and 68 of them were eligible and enrolled in the study. A total of 478 measurements of BNP and HS were performed, representing a mean of 7 measurements per patients (minimum of 2 and maximum of 12). Patient characteristics are shown in table 1 . The median age was 63 years (43-71) and $52.9 \%$ were male. The median duration of PD in non-incident patients was 25 (14-46) months. The modality of treatment was automated PD in $33.8 \%$ and continuous ambulatory PD in $66.2 \%$.

Of the 478 measurements performed, 270 (56.5\%) indicated HS >+1.1 liters, while 177 (37.0\%) were found between -1.1 and +1.1 liters, and $31(6.5 \%)$ had values of HS $<-1.1$ liters.

There was a statistically significant difference in BNP levels between HS groups ( $\mathrm{p}<0.001)$ with a mean rank of $178.9 \mathrm{pg} / \mathrm{ml}$ for group A, $215.2 \mathrm{pg} / \mathrm{ml}$ for group B, and $262.4 \mathrm{pg} / \mathrm{ml}$ for group C (fig. 1). 


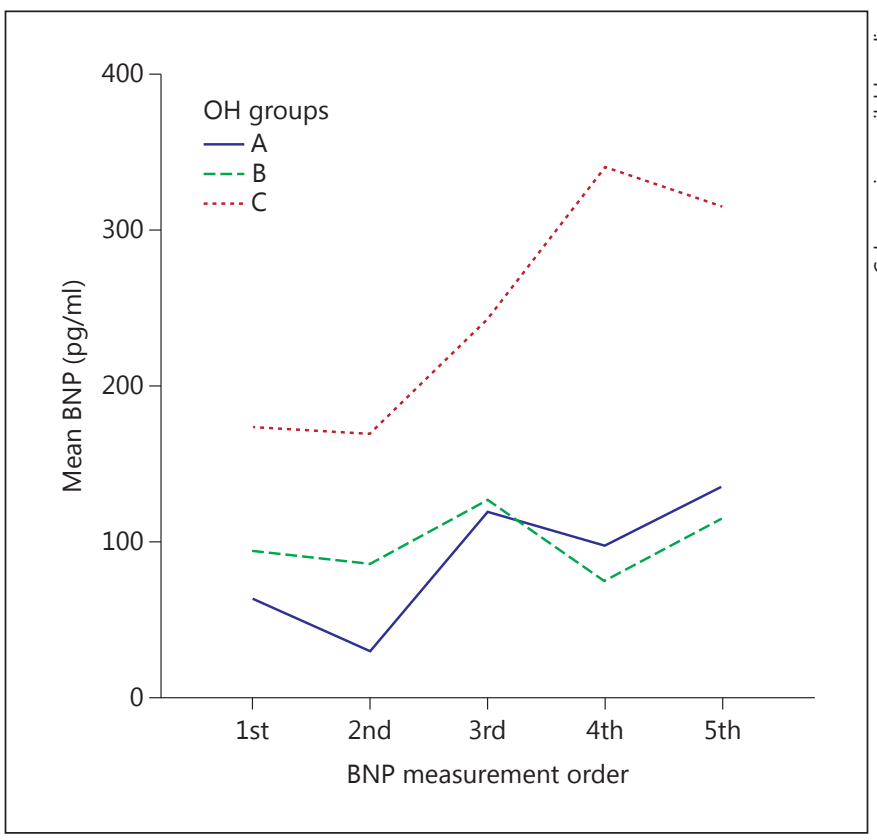

Fig. 1. Mean BNP levels obtained at each assessment.

The median HS measured during the first 6 months on PD was higher than the median HS after 6 months of treatment. The difference of HS between these two groups was statistically significant with a mean rank of $288.3 \mathrm{pg} /$ $\mathrm{ml}$ for the former and of $234.8 \mathrm{pg} / \mathrm{ml}$ for the last $(\mathrm{p}=$ 0.016 ), while no statistically significant difference in BNP levels was found ( $\mathrm{p}=0.663)$ (table 2).

Using Spearman's rank order correlation, we found a significant positive correlation between BNP levels and HS considering the entire sample $(\mathrm{p}<0.001)$ and also when separate analysis was performed for the subgroups and according to time on PD. The correlation was much stronger in the group with shorter PD duration $<6$ months (table 3).

\section{Discussion}

The achievement of euvolemia in PD patients is a fundamental measure of care since volume overload is an independent predictor of mortality in this population [10]. However, the measurement of volume status is not easy in PD patients, despite the availability of several methods that have been developed to help clinicians [19].

In the cohort studied, for more than $50 \%$ of the BIS measurements, the HS was higher than +1.1 liters. Simi-
Table 1. Baseline characteristics of the population at the time of the first assessment

Age, years

Male gender

$63(43-71)$

$36(52.9 \%)$

Caucasian

Incident patients $<3$ months

$63(92.6 \%)$

$19(27.9 \%)$

Duration of RRT, months

$17(2-45)$

Duration of PD, months

$17(2-40)$

Duration of PD on non-incident patients, months

Patients on $\mathrm{PD} \geq 24$ months

$25(14-46)$

$25(36.8 \%)$

Urine volume $/ 24 \mathrm{~h}, \mathrm{ml}$

Anuric

$900(325-1,575)$

$12(17.6 \%)$

Cause of CKD

Diabetic nephropathy $\quad 14(20.6 \%)$

Nephrosclerosis

$20(29.4 \%)$

Glomerulonephritis

$10(14.7 \%)$

ADPKD

$12(17.6 \%)$

$5(7.4 \%)$

Others

$7(10.3 \%)$

PD characteristics

Predominant PD modality

APD

CAPD

$23(33.8 \%)$

$45(66.2 \%)$

Use of furosemide

Daily dose of furosemide (mg) for

$53(77.9 \%)$

patients who used furosemide

$312.5(200-500)$

$\mathrm{RRT}=$ Renal replacement therapy; ADPKD = autosomal dominant polycystic kidney disease; APD = automated peritoneal dialysis; CAPD = continuous ambulatory peritoneal dialysis.

larly, the median HS defined by BIS was always $>+1.1$ liters, regardless if the measurements were performed before 6 months or after a period of 6 months on PD, indicating that more than half of these patients had fluid overload during the study (table 2). This is not surprising as a high prevalence of fluid overload in PD patients was also found by other authors $[20,21]$. Importantly, this finding is associated with increased mortality [10].

After the division of the groups by HS, we found that BNP levels were higher in HS group C (overhydrated) and lower in HS group A (underhydrated) and the difference between the three HS groups was statistically significant $(\mathrm{p}<0.001)$. This observation seems to confirm that higher levels of BNP are present in overhydrated patients independently of their cardiac status. In the Spearman's rank order correlation, BNP levels and HS positively correlated. Other authors have also established a positive correlation between natriuretic peptides and HS in PD patients. Gangji et al. [14], in a cross-sectional 
Table 2. Comparison between HS and BNP levels according to the time on PD on the day of the assessment

\begin{tabular}{lllllll}
\hline & \multicolumn{2}{l}{ Median HS, liter } & $\mathrm{p}$ & \multicolumn{2}{l}{ Median BNP, pg/ml } & $\mathrm{p}$ \\
\hline$<6$ months $(\mathrm{n}=42)$ & 1.9 & 288.3 & 0.016 & 75 & 248.4 & 0.663 \\
$\geq 6$ months $(\mathrm{n}=436)$ & 1.4 & 234.8 & & 87.5 & 238.7 & \\
\hline
\end{tabular}

Table 3. Spearman's rank order correlation between HS and BNP according to the time on PD on the day of the assessment

\begin{tabular}{llll}
\hline & All measurements & \multicolumn{2}{l}{ Measurements performed on PD } \\
\cline { 3 - 4 } & BNP & BNP, $<6$ months & BNP, $\geq 6$ months \\
\hline HS & $\mathrm{r}_{\mathrm{s}}=0.28 ;$ & $\mathrm{r}_{\mathrm{s}}=0.42 ;$ & $\mathrm{r}_{\mathrm{s}}=0.26 ;$ \\
& $\mathrm{p}<0.001$ & $\mathrm{p}=0.006$ & $\mathrm{p}<0.001$ \\
\hline
\end{tabular}

study of 22 PD patients, showed that NT-pro-BNP levels positively correlate with ECW/TBW ratio $\left(\mathrm{r}_{\mathrm{s}}=0.45 ; \mathrm{p}=\right.$ $0.04)$. More recently, in a larger cohort, Papakrivopoulou et al. [16] demonstrated that the patients in the highest NT-pro-BNP quartile had increased ECW/TBW ratio. An interesting finding of the present study is the fact the correlation between BNP and HS was less robust when all the assessments were included, but its strength increased if the data of the first 6 months of treatment was considered separately (from $r_{s}=0.28$ to $r_{s}=0.42$ ). This may be related to the fact that during the early period after the initiation of $\mathrm{PD}$, patients tend to be more overhydrated and over time, their volume status improves. An alternative explanation would be that over time, overhydrated PD patients develop cardiac changes that render BNP a less effective biomarker for volume status. Serial echocardiographic findings are needed to assess this possibility. Finally, changes in peritoneal transport characteristics or decreases in residual renal function may account for these time-dependent changes in the operational characteristics of BNP measures.

The usefulness of natriuretic peptides in the diagnosis of volume status and cardiovascular risk has been studied in recent years and debate still exists on whether they represent reliable biomarkers in the assessment of volume status in CKD patients. For PD in particular, some authors found a positive correlation between natriuretic peptides and HS $[14,16]$, while others could not establish a relationship, but instead found a positive correlation with left ventricle mass index and a negative correlation with left ventricle ejection fraction [22]. Furthermore, NT-pro-BNP has shown to have a high negative predictive value for the presence of systolic dysfunction [23] and to be associated with overall and cardiovascular mortality [9-11]. A limitation is that most of the studies that established correlations are cross-sectional and with relative small populations. Furthermore, the time patients were on PD was highly variable in those cohorts and the same is true for ours, representing a limitation of the study due to heterogeneity of the studied population. Possibilities to test a more homogeneous population are either to use only incident patients or to divide the studied population based on treatment duration. With time, peritoneal transport characteristics change [24] contributing to changes in ultrafiltration that can be detected in the follow-up. Additionally, residual renal function deteriorates over time and is accompanied by more adverse cardiovascular, inflammatory, nutritional and metabolic profiles with increased mortality [25]. Because of these changes that occur in $\mathrm{PD}$ patients over time, we analyzed the correlation between $\mathrm{BNP}$ and HS considering PD duration and we concluded that this correlation is stronger in the first months of treatment. As follow-up duration increases, BNP concentration may be elevated mainly due to higher prevalence of cardiovascular disease and less because of fluid overload.

Our study has several strengths, including a large number of measurements and prospective analysis. Considering the possible changes in PD patients over time, the separate analysis according to time on PD increased the strength of our results. We also recognize some limitations in our study, namely the lack of information on cardiovascular indexes. We did exclude patients with symptoms of heart failure, but we cannot rule out the possibility that they have structural alterations in the myocardium that may contribute to BNP elevations. Since our exclusion criteria were only based on clinical symptoms and without measured cardiovascular indexes, we must consider our results as hypothesisgenerating concepts. Multiple factors influence BNP levels among dialysis patients, including fluid overload, 
hypertension and left ventricular hypertrophy. Additionally, BNP tends to accumulate with decreased renal clearance and renal replacement therapies, including $\mathrm{PD}$, contribute to the removal of these molecules, adding more complexity to this issue and complicating the interpretation of BNP levels in this population. The lack of knowledge of BNP clearance by PD is a limitation of our work, similarly to other authors that have studied BNP in PD patients.
In conclusion, this study demonstrates that BNP correlates positively with fluid overload and this correlation seems to be stronger in the first months of treatment. Larger cohorts and analysis by more homogeneous subgroups are still required to better establish the real impact of BNP as a marker of fluid overload. However, in circumstances where the volume status may be uncertain, BNP measurements may serve as additional clinical information to make change in the PD prescription.

\section{References}

1 Krediet RT: Dry body weight: water and sodium removal targets in PD. Contrib Nephrol. Basel, Karger, 2006, vol 150, pp 104-110.

2 Woodrow G, Devine Y, Cullen M, Lindley E: Application of bioelectrical impedance to clinical assessment of body composition in peritoneal dialysis. Perit Dial Int 2007;27:496-502.

- 3 Konings CJ, Kooman JP, Schonck M, CoxReijven PL, van Kreel B, Gladziwa U, Wirtz J, Gerlag PG, Hoorntje SJ, Wolters J, Heidendal GA, van der Sande FM, Leunissen KM: Assessment of fluid status in peritoneal dialysis patients. Perit Dial Int 2002;22:683-692.

4 Wabel P, Chamney P, Moissl U, Jirka T: Importance of whole-body bioimpedance spectroscopy for the management of fluid balance. Blood Purif 2009;27:75-80.

5 Woodrow G, Ronco C: Assessment of fluid status in peritoneal dialysis. Contrib Nephrol. Basel, Karger, 2012, vol 178, pp 164-168.

6 Logeart D, Thabut G, Jourdain P, Chavelas C, Beyne P, Beauvais F, Bouvier E, Solal AC: Predischarge B-type natriuretic peptide assay for identifying patients at high risk of re-admission after decompensated heart failure. J Am Coll Cardiol 2004;43:635-641.

7 Martinez-Rumayor A, Richards AM, Burnett JC, Januzzi JL Jr: Biology of the natriuretic peptides. Am J Cardiol 2008;101:3-8.

-8 Naganuma T, Sugimura K, Wada S, Yasumoto R, Sugimura T, Masuda C, Uchida J, Naka$\operatorname{tani} \mathrm{T}$ : The prognostic role of brain natriuretic peptides in hemodialysis patients. Am J Nephrol 2002;22:437-444.

-9 Paniagua R, Amato D, Mujais S, Vonesh E, Ramos A, Correa-Rotter R, Horl WH: Predictive value of brain natriuretic peptides in patients on peritoneal dialysis: results from the ADEMEX trial. Clin J Am Soc Nephrol 2008; 3:407-415.

10 Paniagua R, Ventura MD, Avila-Diaz M, Hinojosa-Heredia H, Mendez-Duran A, CuetoManzano A, Cisneros A, Ramos A, MadoniaJuseino C, Belio-Caro F, Garcia-Contreras F, Trinidad-Ramos P, Vazquez R, Ilabaca B, Alcantara G, Amato D: NT-proBNP, fluid vol- ume overload and dialysis modality are independent predictors of mortality in ESRD patients. Nephrol Dial Transplant 2010;25: 551-557.

11 Wang AY, Lam CW, Yu CM, Wang M, Chan IH, Zhang Y, Lui SF, Sanderson JE: N-terminal pro-brain natriuretic peptide: an independent risk predictor of cardiovascular congestion, mortality, and adverse cardiovascular outcomes in chronic peritoneal dialysis patients. J Am Soc Nephrol 2007;18:321-330.

-12 Zoccali C, Mallamaci F, Benedetto FA, Tripepi G, Parlongo S, Cataliotti A, Cutrupi S, Giacone G, Bellanuova I, Cottini E, Malatino LS: Cardiac natriuretic peptides are related to left ventricular mass and function and predict mortality in dialysis patients. J Am Soc Nephrol 2001;12:1508-1515.

13 Fagugli RM, Palumbo B, Ricciardi D, Pasini P, Santirosi P, Vecchi L, Pasticci F, Palumbo R: Association between brain natriuretic peptide and extracellular water in hemodialysis patients. Nephron Clin Pract 2003;95:c60-c66.

-14 Gangji AS, Helal BA, Churchill DN, Brimble KS, Margetts PJ: Association between N-terminal propeptide B-type natriuretic peptide and markers of hypervolemia. Perit Dial Int 2008;28:308-311.

15 Lee SW, Song JH, Kim GA, Lim HJ, Kim MJ: Plasma brain natriuretic peptide concentration on assessment of hydration status in hemodialysis patient. Am J Kidney Dis 2003;41: 1257-1266.

16 Papakrivopoulou E, Lillywhite S, Davenport A: Is N-terminal probrain-type natriuretic peptide a clinically useful biomarker of volume overload in peritoneal dialysis patients? Nephrol Dial Transplant 2012;27:396-401.

17 Haapio M, Honkanen E, Ronco C: Brain natriuretic peptide in peritoneal dialysis patients. Contrib Nephrol. Basel, Karger, 2009, vol 163, pp 110-116.

18 Wabel P, Moissl U, Chamney P, Jirka T, Machek P, Ponce P, Taborsky P, Tetta C, Velasco N, Vlasak J, Zaluska W, Wizemann V: Towards improved cardiovascular management: the necessity of combining blood pressure and fluid overload. Nephrol Dial Transplant 2008;23:2965-2971.

19 Crepaldi C, Lamas EI, Martino FK, Rodighiero MP, Scalzotto E, Wojewodzka-Zelezniakowicz M, Rosner MH, Ronco C: Bioimpedance and brain natriuretic peptide in peritoneal dialysis patients. Contrib Nephrol. Basel, Karger, 2012, vol 178, pp 174-181.

20 Konings CJ, Kooman JP, Schonck M, Dammers R, Cheriex E, Palmans Meulemans AP, Hoeks AP, van Kreel B, Gladziwa U, van der Sande FM, Leunissen KM: Fluid status, blood pressure, and cardiovascular abnormalities in patients on peritoneal dialysis. Perit Dial Int 2002;22:477-487.

21 Van Biesen W, Williams JD, Covic AC, Fan S, Claes K, Lichodziejewska-Niemierko M, Verger C, Steiger J, Schoder V, Wabel P, Gauly A, Himmele R: Fluid status in peritoneal dialysis patients: The European Body Composition Monitoring (EuroBCM) study cohort. PLoS One 2011;6:e17148.

22 Lee JA, Kim DH, Yoo SJ, Oh DJ, Yu SH, Kang ET: Association between serum N-terminal pro-brain natriuretic peptide concentration and left ventricular dysfunction and extracellular water in continuous ambulatory peritoneal dialysis patients. Perit Dial Int 2006;26: 360-365.

23 Wang AY, Lam CW, Wang M, Chan IH, Lui SF, Zhang Y, Sanderson JE: Diagnostic potential of serum biomarkers for left ventricular abnormalities in chronic peritoneal dialysis patients. Nephrol Dial Transplant 2009;24: 1962-1969.

24 Heimburger O, Wang T, Lindholm B: Alterations in water and solute transport with time on peritoneal dialysis. Perit Dial Int 1999; 19(suppl 2):S83-S90.

25 Wang AY, Woo J, Wang M, Sea MM, Sanderson JE, Lui SF, Li PK: Important differentiation of factors that predict outcome in peritoneal dialysis patients with different degrees of residual renal function. Nephrol Dial Transplant 2005;20:396-403. 